\title{
Pathomorphological and Immunohıstochemical Evaluation of Unilateral Progressive Mooren's Ulcer in a Cat
}

\author{
Mehmet Eray Alcigir'1, Tuncer Kutlu², Irem Ergin ${ }^{3}$, Sefika Karabulut ${ }^{4}$ \& Gunay Alcigir ${ }^{5}$
}

\begin{abstract}
Background: Mooren's ulcer is a chronic and painful ulceration of the cornea. It begins progressively in the periphery and spread centrally in cornea. In human, it is seen uniaterally in most of cases. Mooren ulcer has not been reported in any kind of animals up to now. Although its aetiology is not completely enlighted, it has been suspected of the inflammatory reaction against injuries-microbiological and immun mediated effects. Immun response in presence of accumulation of immune complexes into the limbal vessels. As a result of the deficit in the regulatory mechanism because the number of suppressor cells control over B and T lymphocytes, These situations can result in a progressive tendancy to inflammation because the production of autoantibodies and/or lymphokine from cytotoxic T-lymhocytes creates an immune-mediated vasculitis. Numerous immigrant inflammatory cells and proteins are evaded from vessels. After triggering inflammatory cells and releasing of meditors, corneal vascularization, scar tissue and re-epithelization develop. This regenerative-reperative process plays an important role during post-inflammatory process.

Case: In this case, it was aimed to detect pathomorphological structure and immunologic relations in progressive Mooren's ulcer (MU). A 1 year-old mix breed cat was submitted to clinic with complaints of progressive painful and eyesight loss in left eye. There were $1 \mathrm{~cm}$-ulceration, opacification and old haemorrhagic areas at peripheral cornea. Histopathologically, there was wide ulceration including all layers of corneal epithelium and particularly vacuolar degeneration at suprabasal cells. In corneal stroma, numerous neutrophiles and mononuclear cells were infiltrated. Neovascularisation and fibrosis beginning from limbus were also present. This fibrotic progress was confirmed by Masson's trichrome staining method. Immunohistochemically, Cytokeratin 3 (CK3) and cytokeratin 12 (CK12) positivities showing regenerative activity of suprabasal and basal cells were not widespread. Epidermal Growth Factor (EGF) positivities were generally weak in epithelial cells. In stroma, moderate vimentin positivities were detected proliferated in fibrocytes originating from limbus. $\alpha 1-$ antichymotrypsin (A1AC) was mildly reacted in neutrophiles. CD3 and CD4 confirmed the presence of regulatory and helper T lymphocytes. CD3 and CD8 marked cytotoxic T lymphocytes and CD20 marked B lymphocytes in inflammatory areas. CD34 were also positive in peripheral corneal stem cells derived from limbal basal epitheliums in partly regenerated area. CD57 positivity in T lymphocytes and NK cells and CD68 positivity in macrophages were attended to the area. Discussion: CD1a positivity in T lymphocytes proved mediating lipid and microbial origin glycolipid antigens. TUNEL reactions showing DNA in situ fragmentation were present in the destructive and aging epithelial cells at periphery. In conclusion, the case has been found as unique in terms of its immunohistochemical characterization. The markers show that CD1a and CD68 expressions follow different progress in animals unlike in humanbeings even though the ulcer of pathogenetic mechanism is found identical to humanbeings.. The roles of CD20 and CD57 markers have potential roles in this ulcer. It is also concluded that insufficient epithelial regeneration, fibrosis, inflammation and apoptosis showed progressive Mooren's ulcers having possibly microbial origin.
\end{abstract}

Keywords: Mooren's ulcer, pathomorphology, immunohistochemistry, cat. 
M.E. Alcigir, T. Kutlu, I. Ergin, S. Karabulut \& G. Alcigir. 2018. Pathomorphological and Immunohistochemical

\section{INTRODUCTION}

Mooren's ulcer (MU) is a chronic ulceration of the cornea. It begins peripherally and progresses centrally and circumferentially [12,17]. It is a higly rare disease when compared to other ulceration types between corneal diseases. Its etiopathogenesis has remain unknown in spite of being described by Mooren in 1867 [17]. It generally does not give response to medical treatments, and the visual outcome can be poor after surgical intervention $[6,17]$.

Histopathogically, predominantly plasma cells and lymphocytes as well as neutrophils, eosinophils and mast cells stroma on basis of autoimmun disorder are seen in unilateral nonprogressive form. There have been necrotic debris, free eritrocytes and inflammatory cells at the peripheral part of the ulcer in bilateral progressive form. The overlying epithelium and Bowman's membrane are absent. However, the corneal stroma is partly affected toward to central side of the ulcer when compared to periphery [12].

There are a few report regarding its molecular characterization. In these reports, c kit, STRO-1, CD45RO, VCAM, HSP, TNF as well as the markers studied in this case were evaluated $[8,24]$. However, CD20 has not been reported for B lymphocytes on which is known as the surface protein at beginning of the pro-B phase (specific marker: CD45R and CD117). And also CD57 is not mentioned among above cited reports. But, the marker is reported as useful for Natural Killer cell activity and adaptive immune response against viral infected cells [21].

The authors believe that the progressiveagressive MU cases can be also encountered in animals.

\section{CASE}

A 1 year-old mix breed cat was submitted to clinic of Department of Surgery, Ankara University, Faculty of Veterinary Medicine with complaints of progressive painful and eyesight loss and mucopurulent discharge for $1^{1 / 2}$-month. Previously, it was learned from anemnesis that the cat was Feline Immunodeficiency virus positive after diagnosis with FIV Combo rapid test in a private clinic. In clinical examination, a corneal ulceration was detected in left eye. Conjuctiva of left palpebra inferior was also hyperemic. Topical corticosteroids (dexamethasone $0.1 \%$ eye drops) were administered for regression of inflammation during four weeks. Because corneal ulcer did not show any improvement and evaded to central area, the eye was extirpated.

The eye globe was sent to Department of Pathology for diagnosis. The material was evaluated macroscopically. It was put into $10 \%$ buffered formalin solution by being injected into innerside. After fixation, transcoronal sections comprising the corneal ulcer area were done on eye globe. The tissue samples were placed into histocassettes and processed routinely. After embedding in paraffin wax, the blocks were cut at 4 micron thickness. The sections were taken onto nonadhesived slides for haematoxylin and eosin (HE) and Masson's trichrome stainings and adhesive slides for immunohistochemistry, respectively.

Immunohistochemistry was carried out using indirect immunoperoxidase method (ABC-P). After deparaffinization and dehydration, peroxidase activity was blocked for $30 \mathrm{~min}$ by peroxidase blocking reagent (Novocastra Peroxidase Detection Systems, Readyto-use $)^{1}$. Trypsinization was performed by using $0.1 \%$ trypsin solution. Thereafter antigen retrieval solution of sodium citrate $(\mathrm{pH}=6.0)$ [Citrate Buffer 10x, $\mathrm{pH}=6.0$, Bio Optica, BO-15-M103] ${ }^{2}$ was used to rest of antibodies excepting cytokeratin (CK) $3,12^{3}$, vimentin, Epidermal Growth Factor (EPGF) ${ }^{4}$ under $750 \mathrm{~W}$ for 15 min kepting in microwave owen. Non-specific proteins were blocked with protein blocking sera (Novocastra Peroxidase Detection Systems, Ready-to-Use, RE7120$\mathrm{CE})^{1}$. The sections were incubated with all primary antibodies at $45^{\circ} \mathrm{C}$ for $1 \mathrm{~h}$ (Table 1) and followed by biotiynlated link antibody and Horse Radish Peroxidase (HRP) antibody incubation which were applied respectively (Novocastra Peroxidase Detection Systems, Ready-to-Use, RE7120-CE) ${ }^{1}$. 3,3'-diaminobenzidine (DAB-Novocastra Peroxidase Detection System, RE7120-CE) ${ }^{1}$ was selected as chromogen and the sections were kept for $5 \mathrm{~min}$. For counterstaining, Gill's haematoxylin was used. The sections were mounted with nonaqueous mounting medium. For negative tissue control, the tissue sections from healthy cornea were treated with those antibodies. And also, PBS instead of primary antibodies was dropped on ulcerated cornea sections for negative reagent control. For positive tissue controls, $\mathrm{CK} 3,12^{3}$ was treated with rabbit skin, $\mathrm{EPGF}^{4}$ with neonatal mouse skin, vimentin ${ }^{5}$ with mouse skin, Alpha 1 Antichymotrypsin (A1AC) ${ }^{6}$ with rabbit tonsil, $\mathrm{CD} 1 \mathrm{a}^{7}$ with mouse thymus, $\mathrm{CD}^{7}-\mathrm{CD} 4^{7}-\mathrm{CD} 8^{7}-\mathrm{CD} 20^{7}-$ $\mathrm{CD} 34^{7}-\mathrm{CD}^{7} 7^{7}$ and $\mathrm{CD} 68^{7}$ with mouse tonsil. 
M.E. Alcigir, T. Kutlu, I. Ergin, S. Karabulut \& G. Alcigir. 2018. Pathomorphological and Immunohıstochemical

Table 1. Panel of primary antibodies used in the study.

\begin{tabular}{|c|c|c|c|c|c|}
\hline Antibody & Type & Dilution & $\begin{array}{l}\text { Manufacturer } \\
\text { information }\end{array}$ & $\begin{array}{l}\text { Antigen } \\
\text { Retrieval }\end{array}$ & Using aim \\
\hline cytokeratin $3-12$ & mAb mouse anti rabbit & $1: 40$ & US Biological & No & $\begin{array}{l}\text { Detecting of regeneration } \\
\text { in corneal epithelium and } \\
\text { limbal basal cells }\end{array}$ \\
\hline EPGF & pAb rabbit anti mouse & $1: 100$ & Sigma & No & $\begin{array}{l}\text { Detecting of migrational } \\
\text { corneal epithelial cells }\end{array}$ \\
\hline Vimentin, v9 clone & mAb mouse anti pig & $1: 100$ & Milipore & No & $\begin{array}{l}\text { Detecting of fibrocytic and } \\
\text { fibroblastic actitivity }\end{array}$ \\
\hline $\mathrm{A} 1 \mathrm{AC}$ & pAb rabbit anti human & $1: 100$ & Abcam & Yes & $\begin{array}{l}\text { Detecting of keratinocytic } \\
\text { activity after inflammation } \\
\text { during corneal remodeling }\end{array}$ \\
\hline CD1a, Mtb1 clone & $\mathrm{mAb}$ anti mouse & Ready to use & Leica & Yes & $\begin{array}{l}\text { Detecting of limbal cell } \\
\text { proliferation }\end{array}$ \\
\hline CD3, Ps1 clone & $\mathrm{mAb}$ anti mouse & Ready to use & Leica & Yes & $\begin{array}{c}\text { Detecting in T lymphocytes } \\
\text { and Langerhans cell } \\
\text { proliferation of cornea }\end{array}$ \\
\hline CD4, 4b12 clone & $\mathrm{mAb}$ anti mouse & $1: 100$ & Leica & Yes & $\begin{array}{l}\text { Detecting of primarily } \mathrm{T} \\
\text { helper lymphocytes }\end{array}$ \\
\hline CD8, 4b11 clone & $\mathrm{mAb}$ anti mouse & Ready to use & Leica & Yes & $\begin{array}{l}\text { Detecting of primarily } \mathrm{T} \\
\text { cytotoxic lymphocytes }\end{array}$ \\
\hline CD20, L26 clone & $\mathrm{mAb}$ anti mouse & Ready to use & Leica & Yes & $\begin{array}{l}\text { Detecting of B lymphocytes } \\
\text { and stromal stem cells }\end{array}$ \\
\hline CD34, QBend/10 clone & $\mathrm{mAb}$ anti mouse & $1: 100$ & Leica & Yes & $\begin{array}{c}\text { Detecting of B lymphocytes, } \\
\text { stromal stem cells and } \\
\text { epithelial cells }\end{array}$ \\
\hline CD57, 514h12 clone & $\mathrm{mAb}$ anti mouse & Ready to use & Leica & Yes & $\begin{array}{l}\text { Detecting of stromal NK } \\
\text { cells and macrophages }\end{array}$ \\
\hline CD68, nk1 clone & $\mathrm{mAb}$ anti mouse & Ready to use & Leica & Yes & $\begin{array}{l}\text { Detecting of stromal NK } \\
\text { cells and macrophages }\end{array}$ \\
\hline
\end{tabular}

$\mathrm{mAb}=$ monoclonal antbody; $\mathrm{pAb}=$ polyclonal antibody; $\mathrm{RTU}=$ Ready to use.

The remain of procedures was the same with the others. For detection of programmed cell death by TUNEL reaction, DNA fragmentation was assessed in situ in sections using the terminal deoxynucleotidyl transferase (TdT)-mediated dUTP-digoxigenin nick endlabelling (TUNEL) method following catalog procedure (In Situ Cell Death Detection Kit, POD, Roche $)^{8}$. The remain of procedures were the same in immunohistochemistry. For a positive control, the sections were incubated with DNase I $(3000 \mathrm{U} / \mathrm{mL}$ in $50 \mathrm{mM}$ Tris- $\mathrm{HCl}, \mathrm{pH}$ 7.5, $1 \mathrm{mg} / \mathrm{mL}$ BSA) for $10 \mathrm{~min}$ at room temparature before labeling procedure. For a negative control, the samples were treated with labeling solution instead of TdT. All sections were examined using a light microscope (Euromex) and semiquantitavely score calculating after counting haphazardly labelled corneal epithehlial (superficial, suprabasal, basal, limbal cells), inflammatory cells (macrophages, lymphocytes and neutrophyle leucocytes) and fibrocyte-fibroblasts on immunreacted areas at 10 high-power fields (HPF; 400x magnification). The scoring system was graded as: negative (no staining), mild (10-30\%), moderate (30-70\%) and strong (70-100\%).

Macroscopically, the ulcerative area was in 1 $\mathrm{cm}$ in diameter located at peripheral cornea. In addition, a light opacification and old-haemorrhagic areas with brownish red color were attended on the ulceration at corneal periphery. Histopathologically, structure of intact epithelial cells and basement membran integrity were destructed in a widely field. On the other hand, vacuolar degeneration was seen in especially suprabasal cells. Numerous neutrophil leucocytes, other mononuclear cells (mostly macrophages and lymphocytes) were infiltrated to stroma. Small capillaries showing neovascularisation and fibrosis predominantly composed of fibrocytes were located from limbus into 
corneal stroma. This fibrotic progress was confirmed by Masson's trichrome staining method (Figure 1A and B). Immunohistochemically, vimentin was moderately expressed in proliferative fibrocytes and fibroblasts from limbus to stroma (Figure 1C). In corneal epithelium, CK3-12 mildly reacted and did not give widespread reactions. The positivities showed some regenerative activity in suprabasal and basal epithelial cells (Figure 1D). EPGF positivities were generally weakly in other epithelial cells excepting basal cells (Figure 1E). However, DNA in situ fragmentation reactions were found moderately and strongly positive in nuclei of the degenerated epithelial cells as well as stromal cells at both periphery and centrum of the cornea (Figure 1F). A1AC was moderately reacted in neutrophils (Figure 1G). CD1a was strongly positive in basal cells of limbal, suprabasal and superficial cells (at close location to limbus) peripheral and lymphocytes in stroma of peripheral cornea (Figure 1H). CD3 was moderately positive in lymphocytes and Langerhans cells (Figure 1I). Moreover, CD4 and CD8 positivities were found almost same with each other excepting positivities in central epithelial cells and stromal lymphocytes (Figures $1 \mathrm{~J}$ and K). Additionally, CD20 and CD34 positivities were found moderately in superifical cells and strongly in B lymphocytes and possible stromal stem cells (Figures 1L and M). On the other hand, some mild positivities were obtained from CD57 and CD68. The reactions were very similar to superficial epithelial cells of corneal limbus and periphery. There were also moderate positivities in all stromal NK cells and also macrophages (Figures $1 \mathrm{~N}$ and $\mathrm{O}$ ) [Table 2].

\section{DISCUSSION}

It is hypothesized that pathogenesis of Mooren's ulcer has been resourced by deposition of immune complexes into the limbal vessels. Suppressor cells sometimes can loose their control over B and T lymphocytes; or else, huge amount of IgA can be secreted. These situations can be resulted in the production of autoantibodies and or lymphokine from cytotoxic T-lymphocytes after blocking macrophage infiltration. After a while, an immune-mediated vasculitis is developed relating to accumulation of this products [1]. As result of this reaction, a damage at vessel's wall is carried out. Numerous immigrant inflammatory cells and proteins are evaded from vessels [10,11]. Under these circumstances, several cytokines such as interleukin (IL)- $1 \beta,-6,-8$, tumor necrosis factor- $\alpha$ (TNF- $\alpha$ ) and proteases were secreted from inflammatory cells

Table 2. Results of positivities and localization of the marker expressions and DNA in situ fragmentation in cornea.

\begin{tabular}{|c|c|c|c|c|c|c|c|c|c|c|c|c|c|}
\hline \multirow{2}{*}{ Localization } & \multicolumn{13}{|c|}{ Antibody } \\
\hline & CK3-12 & EPGF & Vimentin & Apoptosis & $\mathrm{A} 1 \mathrm{AC}$ & CD1a & CD3 & $\mathrm{CD} 4$ & CD8 & CD20 & CD34 & CD57 & CD68 \\
\hline \multicolumn{14}{|l|}{ Epithelium } \\
\hline Limbus & + & + & - & - & - & +++ & + & ++ & ++ & + & ++ & + & + \\
\hline Periphery & + & + & - & ++ & - & +++ & + & + & ++ & ++ & ++ & + & + \\
\hline Central & - & - & - & +++ & - & + & - & - & + & + & + & - & - \\
\hline \multicolumn{14}{|l|}{ Stroma } \\
\hline Limbus & - & - & ++ & + & ++ & +++ & ++ & + & ++ & +++ & +++ & ++ & ++ \\
\hline Periphery & - & - & ++ & ++ & ++ & +++ & ++ & ++ & ++ & +++ & +++ & ++ & ++ \\
\hline Central & - & - & + & ++ & - & + & + & - & + & +++ & +++ & + & ++ \\
\hline \multicolumn{14}{|l|}{$\begin{array}{l}\text { Bowman's } \\
\text { membrane }\end{array}$} \\
\hline Limbus & - & - & - & - & - & - & - & - & - & - & - & - & - \\
\hline Periphery & - & - & - & - & - & - & - & - & - & - & - & - & - \\
\hline Central & - & - & - & - & - & - & - & - & - & - & - & - & - \\
\hline
\end{tabular}

CK3-12: cytokeratin 3-12; EPGF: Epidermal Growth Factor; A1AC: Alpha 1 Antichymotrypsin; CD: Cluster of Differentiation; Apoptosis: DNA in situ fragmentation Scoring: -: no staining +: mild (10-30\%) immunopositivity, ++: moderate (30-70\%) immunopositivity, +++: strong (70-100\%) immunopositivity. 


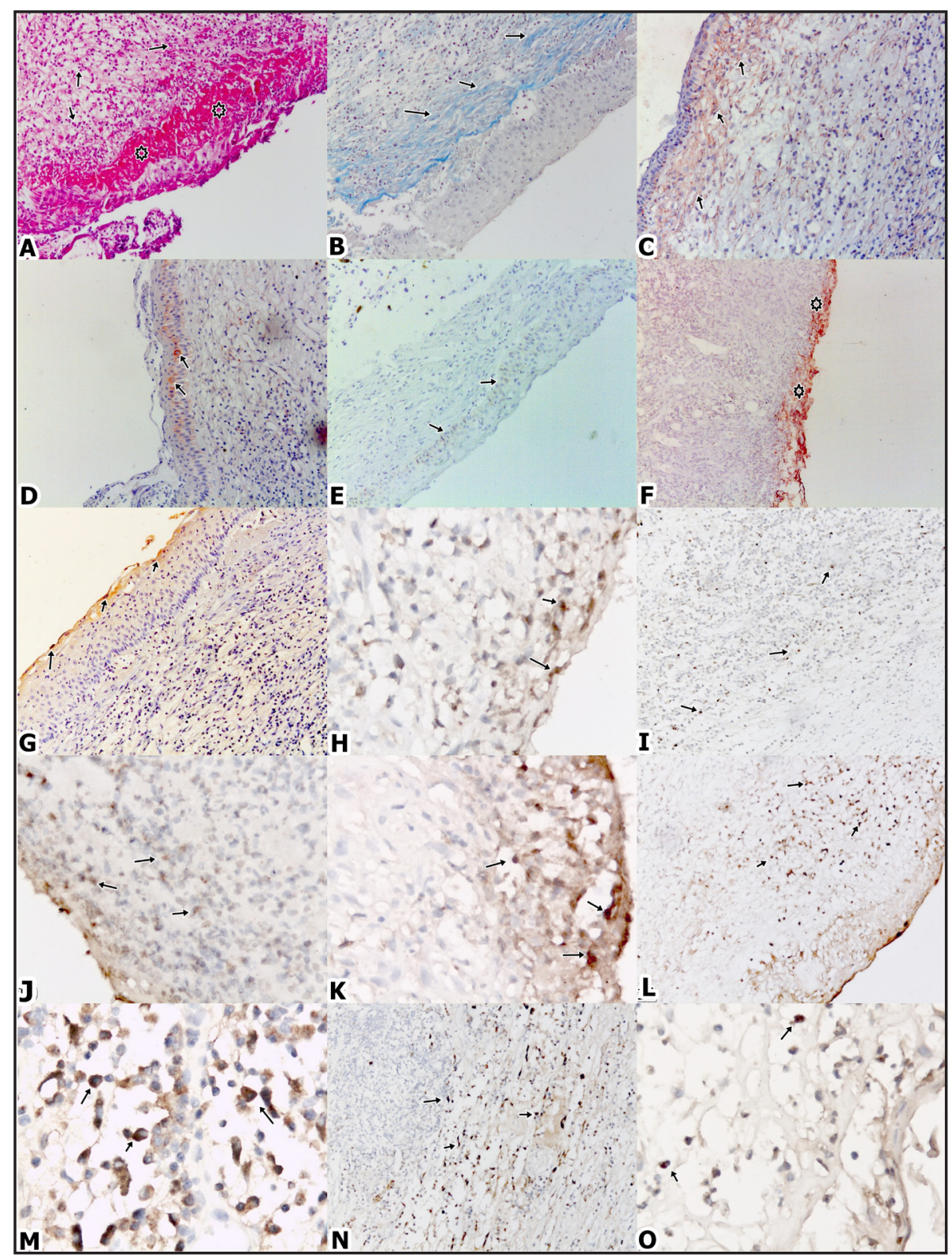

Figure 1. A- Haemorrhagic area and loss of epithelial integrity in ulcerated area (stars), and inflammatory cell infiltration (arrows) [HE, Obj. 100]. B- Subepithelial fibrocytic and fibroblastic activities (arrows) [Masson's Trichrome Staining, Obj.100]. C- Subepithelial fibrocytic and fibroblastic proliferation in stroma (arrows) [vimentin, ABC-P, Obj.100]. D- Positivities in suprabasal cells progressing to ulcerated area (arrows) [CK3-12, ABC-P, Obj. 100]. E- Weak positivenesess of basal cells in peripheral cornea (arrows) [EPGF, ABC-P, Obj. 100]. F- Apoptotic cells in ulcerated area (stars) [TUNEL staining, Obj. 100]. G- A1AC positivities in superficial cells of limbus (arrows) [ABC-P, A1 AC, Obj. 100]. H- CD1a positivities in T-lymphocytes inclining to stroma (arrows) [ABC-P, Obj.400]. I- CD3 positivities in T cells of deep stroma (arrows) [ABC-P, Obj.100]. J- CD4 positivities in Thelper cells and macrophages (arrows) in stromal junction of ulcerated area [ABC-P, Obj.400]. $\mathrm{K}-\mathrm{CD} 8$ positivities in T cytotoxic lymphocytes (arrows) at stromal junction in ulcerated area [ABC-P, Obj.400]. L- CD20 positivities in B lymphocytes in peripheral stroma (arrows) [ABC-P, Obj. 100]. M- CD34 positivities in possible stromal stem cells of peripheral stroma [ABC-P, Obj. 400]. N- CD57 positivities in stromal NK cells [ABC-P, Obj. 100]. O- CD68 positivities in macrophages and lymphocytes in stroma [ABC-P, Obj.400].

$[3,19]$. From one side, neutrophile leucocytes release collagenase, the other side the chemotactic factors lead to stimulation of progenitor cells and keratinocytes [2]. Afterthat, multipotential progenitor cells begin to differentiate into vascular endothelial cells, fibroblasts, and cornea epithelial cells. In this context, developing of corneal vascularization, scar tissue and re-epithelization make meaningfully contribution to the regeneration process after inflammation. Pathogenetic mechanism has been thought under such condition in direction of the results from this study. To the best of author's knowledge, Mooren's ulcer with immunohis- 
tochemical properties is not reported up to know in animals. But, it is interestingly found because the subject was no documented in a cat although such cases were generally documented in its human counterparts. It is reported that Epidermal growth factor (EPGF) stimulates corneal epithelial migration and is responsible for proliferation and differentiation [5,13,23].

On the other hand, it is mentioned that CK312 is a specific marker for mature corneal epithelium $[1,14]$. The marker is especially utilized in detecting limbal stem cells $[15,16]$. In our case, both markers gave weak positivity excepting superficial or basal epithelial cells of cornea. This has showed not enough limbal activity related to epithelial regeneration because MU progresses agrresively. A1AC, alpha globulin glycoprotein, which is called as proteinase inhibitor alpha 1-antichymotrypsin is present and synthesized in the epithelial, stromal and endothelial layers of the human cornea [20]. It is same member of serpin family. It is thought to have a role like alpha 1-antitrypsin protease inhibitor (Pi) which controls the proteolytic action of several enzymes including elastase, collagenase, and trypsin [7,9]. These markers have not been identified up to now in MU. In our case, the positivities from A1AC has thought us that the lesions were still extended under this proteolytic activity. HLA-DR antigen, CD4 and CD8 have found in a large amount of keratoconjunctival epithelial cells at peripheral cornea [22]. Inflammatory cells express CD3, CD4 and CD45RO positively observed in the submucosal connective tissue of the conjunctiva. But, it is reported in a few cases that inflammatory cell express CD8 and CD68 [18]. In our case, moderate positive cells by CD3, CD4 and CD8 are found more distinctive from other primary antibodies. This status may be commented that corticosteroid treatment is helpful because helper and cytotoxic $\mathrm{T}$ lymphocytes activation are dominant in presence of feline immunodeficiency virus (FIV). VCAM-1, which is vascular adhesion protein stimulated by other cytokins, as well as others are found positive in the affected corneal and conjunctival cells, although no significant positivities are described with CD1a, HSP70, and TNF were observed [24]. But, in our case, the inflammatory cells were completely positive as regard CD3, CD4, CD8 and CD68. In a previous report, $\mathrm{CD} 45 \mathrm{RO}$ is found to be positive in infiltrated T and B cells. On the other side, strongly positive in the superficial stromal cells of limbus by CD34. However, positive cells with c-kit and STRO-1 have been observed in that study although there is no reaction by c-kit and STRO-1 [8]. Interestingly, there is no report regarding CD20 and CD57 in such MU cases. Even though there are some reports on roles of those markers during corneal disease in humans, any report could not been found about the incurable corneal ulcer with progressive course in animals.

On the other side, Feline immunodeficiency virus or FIV may be a reason for an acquired immunodeficiency syndrome. In such retroviral infections, the risk of opportunistic infections is risen [4]. But, there is no any documentation in a FIV infected cat. In that case, MU is found asscociated with activity $\mathrm{CD}^{+} \mathrm{T}$ lymphocytes within immune reconstitution inflammatory syndrome (IRIS). This case has showed us MU has been developed under same mechanism.

It is in the case detected as unilateral progressive MU. The case has been found as unique in terms of its immunohistochemical characterization. The markers show us CD1a and CD68 expressions follow different progress in animals in spite of similarly results from others. At the same time, thanks to this case report, the roles of CD20 and CD57 markers have been newly proven in the immunological process with other markers. It is also believed that EPGF and CK3-12 showed weak epithelial proliferative activity including limbal stem cell. A1AC for demonstrating proteolytic activity and vimentin for proliferative fibroblasts have been found usefully in progressive MU. Especially, last mentioned markers have been strongly suggested to be studied in this field.

In conclusion, all selected markers should detect immunological process and make a meaningfull correlation with infectious agent or immunodeficiency situation in incurable MU cases.

\section{MANUFACTURERS}

${ }^{1}$ Leica Biosystems Newcastle Ltd. Nussloch, Germany.

${ }^{2}$ Bio Optica SPA. Milano, Italy.

${ }^{3}$ United States Biological. Salem, MA, USA.

${ }^{4}$ Sigma-Aldrich Corporation. St. Louis, MO, USA.

${ }^{5}$ Merck KGaA. Darmstadt, Germany.

${ }^{6}$ Abcam Inc. Cambridge, MA, USA.

${ }^{7}$ Leica Biosystems Newcastle Ltd. Newcastle, UK.

${ }^{8}$ Roche Diagnostics GmbH. Mannheim, Germany.

Acknowledgements. The case was presented in 4th International Conference and Exhibition on Pathology, 13-15 July 2015, New Orleans, USA.

Declaration of interest. The authors report no conflicts of interest. The authors alone are responsible for the content and writing of the paper. 
M.E. Alcigir, T. Kutlu, I. Ergin, S. Karabulut \& G. Alcigir. 2018. Pathomorphological and Immunohıstochemical

\section{REFERENCES}

1 Espana E.M., Di Pascuale M.A., He H., Kawakita T., Raju V.K., Liu C.Y. \& Tseng S.C. 2004. Characterization of corneal pannus removed from patients with total limbal stem cell deficiency. Investigative Ophthalmology \& Visual Science. 45: 2961-2966.

2 Gottsch J.D., Li Q., Ashraf F., O’Brien T.P., Stark W.J. \& Liu S.H. 1999. Cytokine-induced calgranulin C expression in keratocytes. Clinical Immunology. 91: 34-40.

3 Gregory J.K. \& Foster C.S. 1996. Peripheral ulcerative keratitis in the collagen vascular disease. International Ophthalmology Clinics. 36: 21-30.

4 Hartmann K. 2012. Clinical aspects of feline retroviruses: A review. Viruses. 4: 2684-2710.

5 Ho P.C., Davis W.H., Elliot J.H. \& Cohen S. 1974. Kinetics of corneal epithelial regeneration and epidermal growth factor. Investigative Ophthalmology. 13(10): 804-809.

6 Kalogeropoulos C.D., Malamou-Mitsi V.D., Aspiotis M.B. \& Psilas K.G. 2014. Bilateral Mooren's ulcer in six patients: diagnosis, surgery and histopathology. International Ophthalmology. 25: 1-8.

7 Kalsheker N. 1996. Alpha 1-antichymotrypsin. International Journal of Biochemistry and Cellular Biology. 28: 961-964.

8 Lee I.N. \& Kim J.C. 2005. The involvement of multipotential progenitor cells in Mooren's ulcer. Yonsei Medical Journal. 46: 353-358.

9 Manners R.M., Donaldson M.L., Low C. \& Fenton P.J. 1994. Corneal ulceration in a patient with A1 antitrypsin deficiency. British Journal of Ophthalmology. 78: 653-654.

10 Mondino B.J. 1986. Experimental aspects and models of peripheral corneal disease. International Ophthalmology Clinics. 26: 5-14.

11 Mondino B.J. 1988. Inflammatory disease of the peripheral cornea. Ophthalmology. 95: 463-472.

12 Murray P.I. \& Rahi A.H.S. 1984. Pathogenesis of Mooren's ulcer: some new concepts. British Journal of Ophthalmology. 68: $182-187$.

13 Nishida T., Nakamura M., Murakami J., Mishima H. \& Otori T. 1992. Epidermal growth factor stimulates corneal epithelial cell attachment to fibronectin through a fibronectin receptor system. Investigative Ophthalmology. 33: 2464-2469.

14 Sachetti M., Lambiase A., Cortes M., Sgrulletta R., Bonini S., Merlo D. \& Bonini S. 2005. Clinical and cytological findings in limbal stem cell deficiency. Graefes Archives of Clinical Experimental Ophthalmology. 243: 870-876.

15 Schlötzer-Schrehardt U. \& Kruse F.E. 2005. Identification and characterization of limbal stem cells. Experimental Eye Research. 81: 247-264.

16 Schmer A., Galvin S. \& Sun T.T. 1986. Differentiationrelated expression of a major 64K corneal keratin in vivo and in culture suggests limbal location of corneal epithelial stem cells. Journal of Cellular Biology. 103: 49-62.

17 Seino J.Y. \& Anderson S.F. 1998. Mooren's ulcer. Optometry and Vision Science. 75: 783-790.

18 Shinomaya K., Ueta M., Sotozono C., Inatomi T., Yokoi N., Kouizumi N. \& Kinoshita S. 2013. Immunohistochemical analysis of inflammatory limbal conjunctiva adjacent to Mooren's ulcer. British Journal of Ophthalmology. 97: 362-326.

19Shiuey Y. \& Foster C.S. 1998. Peripheral ulcerative keratitis and collagen vascular disease. International Ophthalmology Clinics. 38: 21-32.

20 Twining S.T., Fukuchi T., Yue B.J.Y.T., Wilson P.M. \& Zhou X. 1994. Alpha 1-antichymotrypsin is present in and synthesized by the cornea. Current Eye Research. 13: 433-449.

21 Vivier E., Raulet D.H., Moretta A., Caligiuri M.A., Zitvogel L., Lanier L.L., Yokoyama W.M. \& Ugolini S. 2011. Innate or adaptive immunity? The example of natural killer cells. Science. 331: 44-49.

22 Wang Z., Chen J.Q. \& Zheng H.L. 1994. An immunohistochemical study of cornea and adjacent bulbar conjunctiva in Mooren's ulcer. Zhonghua Yan Ke Za Zhi. 30: 218-220.

23 Watanabe K., Nakagawa S. \& Nishida T. 1987. Stimulatory effects of fibronectin and EGF on migration of corneal epithelial cells. Investigative Ophthalmology Visual Science. 28: 205-211.

24 Xie H., Chen J., Zheng H., Li Y. \& Liu W. 2000. A histochemical and immunohistochemical study of cornea and adjacent bulbar conjunctiva in Mooren's ulcer. Yan Ke Хue Bao. 16: 139-152. 